Volume 02 Nomor 01, Juni 2020 Page 33-36

Incrementapedia: Jurnal Pendidikan Anak Usia Dini

Program Studi PG-PAUD Fakultas Pedagogik dan Psikologi

Universitas PGRI Adi Buana Surabaya

http://jurnal.unipasby.ac.id/index.php/incrementapedia

e-ISSN: 2686-3146

\title{
MENGEMBANGKAN KEMAMPUAN BERHITUNG PADA ANAK DENGAN PERMAINAN TRADISIONAL CONGKLAK
}

\author{
Andrika Muji Lestaria ${ }^{a}$, Made Ayu Anggreni ${ }^{b}$ \\ ${ }^{a}$ Pendidikan pada Satuan Tingkat Pendidikan Anak Usia Dini, TK Ana Donowati Surabaya \\ email: andrikalestari@yahoo.co.id \\ bProgram Studi Pendidikan Guru Pendidikan Anak Usia Dini \\ Fakultas Pedagogik dan Psikologi Universitas PGRI Adi Buana Surabaya \\ email : madeayu@unipasby.ac.id
}

\begin{abstract}
This research is motivated by the information that the traditional game congklak is considered to improve the children's ability to count. The traditional game congklak is one of the learning media that can improve the children's capability to count. With traditional congklak games it is expected that children can learn to count in a more enjoyable way. The problem formulation in this research is "Does the game tradisoanal congklak affect to the children's capability to count?". The purpose of this study is to determine whether the influence of traditional congklak games on the ability to count early childhood in group B in TK Ana Donowati Surabaya.This research uses pre-experimental design with one-group pretest-posttest design. Subjects in this study were 15 children. Data analysis applied in this research is different test technique of pre-test and post-test ( $t$ test) from observation of children activity to know the capability of children counting through congklak traditional game activity. The results of data analysis show that $t_{\text {hitung }} 8,16$ dan $t_{\text {tabel }} 1,76$ with extent $\alpha 0,05$ and 2,62 at $\alpha 0,01, t_{\text {hitung }}>t_{\text {tabel }}$ so $H_{0}$ rejected and $H_{1}$ (working hypothesis) accepted. It can be concluded that the traditional game congklak has an effect on the ability to count on the group $B$ early childhood TK Ana Donowati Surabaya.
\end{abstract}

Keywords: Traditional Games Congklak, Children's Capability to Count.

\section{PENDAHULUAN}

Tujuan PAUD menurut Sujiono, dkk (2014:7) adalah memberikan stimulasi atau rangsangan bagi perkembangan potensi anak agar menjadi manusia beriman dan bertakwa kepada Tuhan Yang Maha Esa, berakhlak mulia, sehat, berilmu, cakap, kritis, kreatif, inovatif, mandiri, percaya diri, dan menjadi warga Negara yang demokratis dan bertanggung jawab. Salah satu aspek yang harus dikembangkan oleh peserta didik anak yaitu perkembangan kognitif, dimana kognitif adalah suatu proses berpikir, daya menghubungkan serta kemampuan menilai dan mempertimbangkan. Perkembangan kognitif sangatlah penting dikembangkan karena ketika anak masih kecil agar anak dapat melakukan berbagai eksplorasi terhadap dunianya yang ada dilingkungan tempat tinggalnya di rumah. Salah satunya anak akan dikenalkan pada kegiatan berhitung melalui permainan congklak pada rentang usia 5-6 tahun. Salah satu cabang matematika adalah berhitung, berhitung merupakan dasar dari beberapa ilmu yang dipakai dalam setiap kehidupan manusia.

Suyadi dan Ulfah (2013:7-8) menemukan perbedaan yang sangat signifikan antara anak-anak yang masuk lembaga PAUD dengan yang tidak. Hal ini menunjukkan bahwa pendidikan anak usia dini sangatlah penting. Pendidikan Anak Usia Dini dibagi dalam tiga jalur, yaitu jalur formal meliputi 
Taman Kanak-Kanak (TK), jalur non formal meliputi Taman Penitipan Anak (TPA), Kelompok Bermain (KB), dan bentuk lain yang sederajat; serta jalur informal yaitu keluarga. Dalam hal ini penulis menitikberatkan pada jalur formal yaitu Taman Kanak-Kanak (TK).

Pada kenyataan di lapangan yang peneliti lihat di TK Ana Donowati masih banyak anak kelompok B yang berjumlah 15 anak belum mampu berhitung, seperti mengurutkan angka-angka. Karena pentingnya kemampuan berhitung, peneliti ingin memberikan pembelajaran berhitung melalui permainan congklak.

Permainan congklak adalah permainan yang sangat menitikberatkan pada penguasaan berhitung. Dengan permainan tradisional congklak anak dapat bermain sambil belajar berhitung dengan menggunakan biji-biji congklak. Melalui permainan tradisional congklak guru bisa juga mengenalkan bahwa permainan tradisional congklak adalah permainan asli Indonesia.

\section{METODE PENELITIAN}

Sugiyono (2014:7) mengungkapkan bahwa metode kuantitatif dinamakan metode tradisional, karena metode ini sudah cukup lama digunakan sehingga sudah mentradisi sebagai metode untuk penelitian. Metode ini disebut sebagai metode positivistic karena berlandaskan pada filsafat positivisme. Metode ini sebagai metode ilmiah/scientific Karenatelah memenuhi kaidahkaidah ilmiah yaitu konkrit/empiris, obyektif, terukur, rasional, dan sistematis. Metode ini juga disebut metode discovery, karena dengan metode ini dapat ditemukan dan dikembangkan berbagai iptek baru. Metode ini disebut metode kuantitatif karena data penelitian berupa angka-angka dan analisis menggunakan statistik.

Desain penelitian eksperimen yang digunakan dalam penelitian ini yaitu pre eksperimental design. Menurut Arikunto (2013:123) Mengungkapkan ada 3 jenis design yang dimasukkan ke dalam kategori pre experimental design, yaitu (1) One shot case study, (2) Pres test and post test, dan (3) Static Group Comparision.Menurut Sugiyono (2010:193) salah satu hal utama yang mempengaruhi kualitas data hasil penelitian adalah kualitas pengumpulan data.Kualitas pengumpulan data berkenaan dengan ketepatan cara-cara yang digunakan untuk mengumpulkan data. Penelitian ini menggunakan teknik pengumpulan data dengan melakukan observasi.

\section{HASIL PENELITIAN}

Pengumpulan data dan penyajian yaitu dipaparkan dalam bentuk tabel yang selanjutnya dilakukan mencari hasil uji beda antara Pre-test dan Post-test kemudian melakukan uji hipotesis, dan mencari hasil uji signifikansi T-Test ( $\mathrm{t}_{\text {hitung }}$ ). Adapun hasil uji beda Pre-test dan Post-test disajikan dalam bentuk dibawah ini.

Tabel 1Uji Beda Pre tes-Pos test

\begin{tabular}{cccc} 
Subyek & Pre-Test & Post-Test & Gain \\
\hline 1 & 2,72 & 3,41 & 0,69 \\
2 & 2,41 & 2,75 & 0,34 \\
3 & 2,22 & 2,84 & 0,63 \\
4 & 2,41 & 3,19 & 0,78 \\
5 & 2,66 & 3,06 & 0,41 \\
6 & 2,69 & 3,03 & 0,34 \\
7 & 2,16 & 2,53 & 0,38 \\
8 & 2,25 & 2,56 & 0,31 \\
9 & 2,34 & 2,69 & 0,34 \\
10 & 3,03 & 3,25 & 0,22 \\
\hline
\end{tabular}




\begin{tabular}{cccc}
\hline 11 & 2,94 & 3,16 & 0,22 \\
12 & 2,88 & 3,13 & 0,25 \\
13 & 2,94 & 3,25 & 0,31 \\
14 & 2,41 & 3,16 & 0,75 \\
15 & 2,53 & 3,34 & 0,81 \\
$\mathrm{~N}=15$ & 35,56 & 45,34 & \\
& $\bar{x}_{1}=2,57$ & $\bar{x}_{2}=1,18$ & $\sum \mathrm{d}=6,78$ \\
\hline
\end{tabular}

$\mathrm{Md}=\frac{\sum d}{N}=\frac{6,78}{15}=0,45$

Persiapan tabel uji hipoesis dapat dilihat pada tabel 2 dibawah ini.

Tabel 2 Persiapan uji hipotesis

\begin{tabular}{cccc} 
Subyek & $\mathbf{d}$ & $\mathbf{X}_{\mathbf{d}(\mathbf{d}-\mathbf{M d})}$ & $\mathbf{x}^{2} \mathbf{d}$ \\
\hline 1 & 0,69 & 0,24 & 0,06 \\
2 & 0,34 & $-0,11$ & 0,01 \\
3 & 0,63 & 0,17 & 0,03 \\
4 & 0,78 & 0,33 & 0,11 \\
5 & 0,41 & $-0,05$ & 0,00 \\
6 & 0,34 & $-0,11$ & 0,01 \\
7 & 0,38 & $-0,08$ & 0,01 \\
8 & 0,31 & $-0,14$ & 0,02 \\
9 & 0,34 & $-0,11$ & 0,01 \\
10 & 0,22 & $-0,23$ & 0,05 \\
11 & 0,22 & $-0,23$ & 0,05 \\
12 & 0,25 & $-0,20$ & 0,04 \\
13 & 0,31 & $-0,14$ & 0,02 \\
14 & 0,75 & 0,30 & 0,09 \\
15 & 0,81 & 0,36 & 0,13 \\
& $\sum_{d}=6,78$ & & $\sum \mathrm{x}_{\mathbf{d}}^{2}=0,64$ \\
\hline
\end{tabular}

Langkah berikutnya adalah menganalisis hasil penelitian kuantitatif eksperimen yang menggunakan desain Pre-Experimental Design dengan bentuk One-Group Pretest-Postest Design dengan rumus sebagai berikut.

$$
t=\frac{M d}{\sqrt{\frac{\sum X^{2} d}{N(N-1)}}}
$$

Sehingga dapat diperoleh $t_{\text {hitung }} 8,16$

\section{PEMBAHASAN}

Berdasarkan hasil penelitian diketahui bahwa ada pengaruh permainan tradisional congklak terhadap kemampuan berhitung pada anak kelompok B TK Ana Donowati Surabaya. Dengan bermain permainan tradisional congklak anak-anak tidak hanya mendapatkan kesenangan dalam bermain, namun juga meningkatkan kemampuan berhitungnya. Ia dapat belajar berhitung dengan menghitung biji-biji congklak.

Setelah anak-anak bermain permainan tradisional congklak anak lebih tidak bosan dan jenuh dalam pembelajaran berhitung, dengan bermain congklak selain anak-anak dapat menghitung biji-biji congklak anak-anak dapat menaruh biji-biji congklak satu per satu dalam lubang congklak hal ini dapat melatih motorik halus anak. Para guru dan orang tua dapat menerapkan permainan tradisional congklak ini terhadap anak usia dini karena permainan ini mempunyai beberapa peranan diantaranya adalah untuk melatih kemampuan berhitung anak serta kemampuan motorik halus anak. Hal ini benar seperti yang diungkapkan oleh Tedjasaputra.

Hasil dari peneliti setelah menerapkan permainan tradisional congklak anak mulai dapat berhitung dan mengurutkan 1-20 dengan benar, mereka juga dapat mengetahui mana jumlah yang paling banyak dan yang paling sedikit. Mereka yang awalnya sangat bosan dalam pembelajaran berhitung yang hanya dengan menulis kini mereka sangat antusias belajar berhitung dengan permainan congklak.

Terbukti bahwa ada pengaruh permainan tradisional congklak terhadap Kemampuan 
berhitung pada anak kelompok B Di TK Ana Donowati Surabaya. Hal itu ditunjukkan oleh hasil analisis data bahwa $t_{\text {hitung }}$ sebesar 8,16 lebih besar dari $\quad t_{\text {tabel }} 1,76$ pada $\quad \alpha \quad 0,05$ maupun 2,62 pada $\alpha 0,01$. Hal ini menunjukkan bahwa permainan tradisional congklak berpengaruh signifikan pada kemampuan berhitung anak baik pada taraf kepercayaan 95\% maupun 99\%.

Hasil penelitian ini sejalan dengan hasil penelitian yang dilakukan oleh Tedjasaputra dan hasilnya menunjukkan kesamaan bahwa alat permainan edukatif merupakan alat permainan yang dirancang secara khusus untuk bisa memilihkan alat permainan congklak. Melalui Permainan congklak yang merupakan permainan tradisional anak akan dapat belajar berhitung sambil bermain.

\section{SIMPULAN DAN SARAN}

\subsection{Simpulan}

Berdasarkan analisis data yang sudah dilakukan, maka dapat disimpulkan bahwa permainan tradisional congklak berpengaruh terhadap kemampuan berhitung Pada Anak Kelompok B TK Ana Donowati Surabaya.

\subsection{Saran}

Guru diharapkan dapat mengembangkan kemampuan berhitung anak dengan cara bermain permainan tradisional congklak. Guru harus mampu menjadi motivator bagi anak dan dapat menciptakan desain pembelajaran yang menarik bagi anak, sehingga dapat meningkatkan kemampuan berhitung anak melalui bermain. Pihak sekolah diharapkan banyak menyediakan sarana pembelajaran yang menunjang kegiatan belajar anak yang berkaitan dengan kemampuan berhitung melalui pengenalan permainan tradisional.

\section{REFERENSI}

Arikunto, Suharsimi (2013). Prosedur Penelitian Suatu Pendekatan Praktik. Jakarta: Rineka Cipta

Sugiyono (2014). Metode Penelitian Kuantitatif, Kualitatif dan R\&D.Bandung: Alfabeta.

Sujiono, Yuliani Nurani (2009). Konsep Dasar Pendidikan Anak Usia Dini .Jakarta: Indeks.

Suyadi dan Ulfah, Mauldya (2013). Konsep Dasar Paud.Bandung:Remaja Rosdakarya

Tedjasaputra, Mayke S. (2001). Bermain Mainan dan Permainan Untuk Pendidikan Anak Usia Dini. Jakarta:Grasindo. 